\title{
Underexpression of MMP-2 and its Regulators, TIMP2, MT1-MMP and IL-8, is Associated with Prostate Cancer
}

Sabrina Thalita Reis, Alberto Azoubel Antunes, Jose Pontes-Junior, Juliana Moreira de SousaCanavez, Marcos Francisco Dall'Oglio, Camila Belfort Piantino, Jose Arnaldo Shiomi da Cruz, Denis Reis Morais, Miguel Srougi, Katia R. M. Leite

Laboratory of Medical Investigation (LIM55), Urology Department, University of Sao Paulo Medical School, (STR, AAA, JP Jr, MFD, CBP, JASC, DRM, MS, KRML), Sao Paulo, Brazil, Uro-Oncology Group, Urology Department, Instituto do Cancer do Estado de Sao Paulo (ICESP), University of Sao Paulo Medical School, (STR, AAA, JP Jr, MFD, MS, KRML), Sao Paulo, Brazil and Genoa Biotechnology SA, (JMSC) Sao Paulo, Brazil

\section{ABSTRACT}

Objective: Extracellular matrix homeostasis is strictly maintained by a coordinated balance between the expression of metalloproteinases (MMPs) and their regulators. The purpose of this study was to investigate whether MMP-2 and its specific regulators, TIMP-2, MT1-MMP and IL-8, are expressed in a reproducible, specific pattern and if the profiles are related to prognosis and clinical outcome of prostate cancer (PCa).

Materials and Methods: MMP-2, TIMP-2, MT1-MMP and IL-8 expression levels were analyzed by quantitative real-time polymerase chain reaction (qRT-PCR) in freshly frozen malignant and benign tissue specimens collected from 79 patients with clinically localized PCa who underwent radical prostatectomies. The control group consisted of 11 patients with benign prostate hyperplasia (BPH). The expression profile of the MMP-2 and its regulators were compared using Gleason scores, pathological stage, pre-operative PSA levels and the final outcome of the PCa.

Results: The analysis of 79 specimens of PCa revealed that MMP-2, TIMP-2, MT1MMP and IL-8 were underexpressed at 60.0\%, 72.2\%, 62.0\% and 65.8\%, respectively, in malignant prostatic tissue in relation to BPH samples. Considering the prognostic parameters, we demonstrated that high Gleason score tumors $(\geq 7)$ overexpressed MMP-2 $(\mathrm{p}=0.048)$ and TIMP-2 $(\mathrm{p}=0.021)$, compared to low Gleason score tumors $(<7)$.

Conclusion: We have demonstrated that MMP-2 and its regulators are underexpressed in PCa. Alternatively, overexpression of MMP-2 and TIMP-2 was related to higher Gleason score tumors. We postulate that alterations in metalloproteinase expression may be important in the control of tissue homeostasis related to prostate carcinogenesis and tumor behavior.

\section{ARTICLE INFO}

\section{Key words:}

matrix metalloproteinase; prognosis; diagnosis; gene expression; prostate; neoplasms

Int Braz J Urol. 2012; 38: 167-74

Submitted for publication:

May 05, 2011

Accepted after revision:

August 22, 2011

\section{INTRODUCTION}

Prostate cancer (PCa) is a common disease with a multifactorial and complex etiology. It is the most common malignancy in the male and the second leading cause of death in many countries, including Brazil. Estimates for 2011 indicate that 903,500 new cases and 258,400 deaths relat- 
ed to PCa will occur worldwide (1). Tumor staging, Gleason scores and PSA serum values are the most important prognostic factors, but even when used together, they cannot be used to perfectly diagnose patients at risk for progression (2). Therefore, research has been aimed to the identification of molecular markers that can contribute to diagnosis and predict PCa progression.

Degradation of basal membranes and extracellular matrix (ECM) is essential for tumor invasion and development of metastases, and matrix metalloproteinases (MMPs) are potent proteolytic enzymes that are known to play a key role in these processes. Within the MMP family, MMP2 (gelatinase A, $72 \mathrm{kDa}$ ) cleaves type IV collagen and gelatin, which are the main structural components of the basal membrane (3). Expression of MMP2 has been implicated in the development and progression of many neoplasias, such as bladder (4) and colon cancer (5).

MMPs are transcriptionally regulated. MMP2 is mainly regulated by its zymogen inhibitor, tissue inhibitor of metalloproteinase 2 (TIMP2), and by its major activator, membrane type-1 MMP (MT1-MMP), also known as MMP14. MT1-MMP specifically activates the pro-gelatinase, MMP2, on the tumor cell surface in vitro through the formation of a complex with TIMP2 (6). IL8 upregulates MMP2 in tumor cells, which is thought to be responsible for its angiogenic activity (7).

Neoplasia, an imbalance between MMPs and their regulators, leads to excess degradation, which may be linked to the invasive character of tumor cells (8-10). The aim of the present study was to investigate the expression profile of MMP2 and it specific regulators, TIMP2, MT1-MMP and IL8 in prostate cancer, associating them with the three most important prognostic parameters: Gleason score, pathological stage and pre-operatory PSA serum levels. Also, we aimed to relate these profiles to the outcome of patients with localized PCa who underwent radical prostatectomies.

\section{MATERIALS AND METHODS}

\section{Patients}

The study was conducted using surgical specimens from 79 patients with clinically local- ized PCa who underwent radical prostatectomy in our institution between 1993 and 2007. These cases were randomly selected from our database. Patients who had undergone other adjuvant and neoadjuvant treatments for $\mathrm{PCa}$ were excluded from the study. All subjects provided informed consent to participate in the study and to allow their biological samples to be genetically analyzed. The Institutional Board of Ethics approved this study (\#0453/08).

We first analyzed MMP-2, TIMP-2, MT1MMP and IL-8 expression levels in fresh tumor specimens from the 79 PCa patients using quantitative real-time polymerase chain reaction (qRTPCR). The clinical and pathological characteristics of these specimens are listed in Table- 1 . The control group consisted of tissue specimens from 11 patients with benign prostatic hyperplasia (BPH), who had lower urinary tract symptoms and had undergone retropubic prostatectomy (mean age $64 \pm 6.0$ years).

We then correlated the expression levels of the genes with Gleason scores, pathological stage (TNM 2010) and pre-operative serum PSA levels $(\mathrm{ng} / \mathrm{mL})$. For analytical purposes, the pathological stages were described as organ-confined (pT2) or non-organ-confined (pT3) diseases; Gleason scores were classified as low grade (Gleason score $<7$ ) or high grade (Gleason score $\geq 7$ ). Preoperative PSA levels were also used to identify patients at high risk $(\geq 10 \mathrm{ng} / \mathrm{mL}$ ) and low risk $(<10 \mathrm{ng} / \mathrm{mL})$ for disease recurrence. Additionally, we related the gene expression with the biochemical recurrence free survival rate in a mean follow-up time of 60 months, considering PSA levels $>0.4 \mathrm{ng} / \mathrm{mL}$.

\section{RNA Isolation and cDNA Synthesis}

All tumor samples were obtained from surgical specimens and immediately frozen at $-170^{\circ} \mathrm{C}$ in liquid nitrogen. A slide with a mirror of the frozen fragment was stained with hematoxylin and eosin to verify that the tumor represented at least $75 \%$ of the fragment in patients with cancer and to demonstrate the absence of tumor in those with BPH.

Total RNA was isolated with an RNAaqueous Kit (Applied Biosystems, CA, USA) according 
Table 1 - Demographic characteristics of 79 men who underwent a radical prostatectomy treatment for prostate cancer.

\begin{tabular}{lc}
\hline Age (years) & \\
\hline Mean & 63 \\
Min - Max & $41-79$ \\
PSA (ng/mL) & 10.8 \\
Mean & $2.0-37.0$ \\
Min - Max & $47(59.5)$ \\
$<10 \mathrm{n}(\%)$ & $32(40.5)$ \\
$\geq 10 \mathrm{n}(\%)$ & \\
Stage & $38(48)$ \\
pT2 n (\%) & $41(52)$ \\
pT3 $\mathrm{n}(\%)$ & \\
Gleason Score & $33(41.7)$ \\
$<7 \mathrm{n}(\%)$ & $46(58.3)$ \\
$\geq 7 \mathrm{n}(\%)$ & \\
\hline
\end{tabular}

to the manufacturer's instructions. RNA concentration was determined by measuring absorbance at 260/280 nM using a Nanodrop ND-1000 spectrophotometer (Thermo Scientific). cDNA was generated using a High Capacity cDNA Reverse Transcription Kit (Applied Biosystems, CA, USA). The reactions were incubated at $25^{\circ} \mathrm{C}$ for $10 \mathrm{~min}$., followed by $37^{\circ} \mathrm{C}$ for $120 \mathrm{~min}$. and $85^{\circ} \mathrm{C}$ for $5 \mathrm{~min}$. The cDNA was stored at $-20^{\circ} \mathrm{C}$ until further use.

\section{Quantitative Real-Time PCR and Gene Expression}

Expression levels of the four genes were analyzed by qRT-PCR using an ABI 7500 Fast Real-Time PCR System (Applied Biosystems). Target sequences were amplified in a $10 \mu \mathrm{L}$ reaction containing $5 \mu \mathrm{L}$ of TaqMan Universal PCR Master Mix, $0.5 \mu \mathrm{L}$ of TaqMan Gene Expression Assays (primers and probes, see Table-2), $1 \mu \mathrm{L}$ of cDNA and $3.5 \mu \mathrm{L}$ of DNase-free water. The PCR cycling conditions were 2 minutes at $50^{\circ} \mathrm{C}, 10$ minutes at $95^{\circ} \mathrm{C}$, and then 40 cycles of 15 seconds at $95^{\circ}$ $\mathrm{C}$ and 1 min at $60^{\circ} \mathrm{C}$. A TaqMan B2M assay was used as the endogenous control (Table-2).
We used the $\Delta \Delta \mathrm{CT}$ method to calculate the relative expression of the three target genes using the formula $\Delta \Delta \mathrm{CT}=$ (CT target gene, $\mathrm{PCa}$ sample - CT endogenous control, PCa sample) - (CT target gene, BPH sample - CT endogenous control, BPH sample). The fold change in gene expression was calculated as $2-^{\Delta \Delta} \mathrm{CT}$.

\section{Statistical Analysis}

Quantitative variables were expressed as median values, interquartile range (Q1-Q3), and minimum and maximum values. Qualitative variables were expressed as numbers and percentages. To compare the clinical characteristics of patients with PCa, we used the Mann-Whitney, chi-squared and Fisher exact tests. For descriptive analysis of MMP-2, TIMP-2, MT1-MMP and IL-8 expressions according to pathological stage, Gleason scores and PSA levels, we constructed a box plot, and for comparison between categories, we used the Mann-Whitney test. Statistical analysis was performed using SPSS 15.0 for Windows, and significance was set at $\mathrm{p} \leq 0.05$. 


\section{RESULTS}

As shown in Figure1, the analysis of 79 specimens of PCa revealed that MMP-2, TIMP-2, MT1-MMP and IL-8 were underexpressed in malignant prostatic tissue in relation to BPH samples. MMP-2, TIMP-2, MT1-MMP and IL-8 were underexpressed at levels of $60.0 \%, 72.2 \%, 62.0 \%$
$=0.021)$. Only a marginal statistical difference for MT1-MMP was observed between the two tumor groups: the median was 0.89 for high-grade vs. 0.65 for low-grade PCa $(p=0.08)$. There were no differences in the expression levels of IL-8 when considering Gleason scores (Table-3).

There were no differences in the expression levels of the four genes according to the

Table 2 - Primers used in this study.

\begin{tabular}{ll}
\hline Gene symbol & Assays ID \\
\hline MMP2 & Hs00234422_m1 \\
TIMP2 & Hs00234278_m1 \\
MMP14 & Hs00237119_m1 \\
IL-8 & Hs99999034_m1 \\
B2M & Hs99999907_m1 \\
\hline
\end{tabular}

Figure 1 - Expression levels of the four genes in PCa tissue compared to BPH. Fold change in expression was calculated using the $2^{-\Delta c T}$ method.

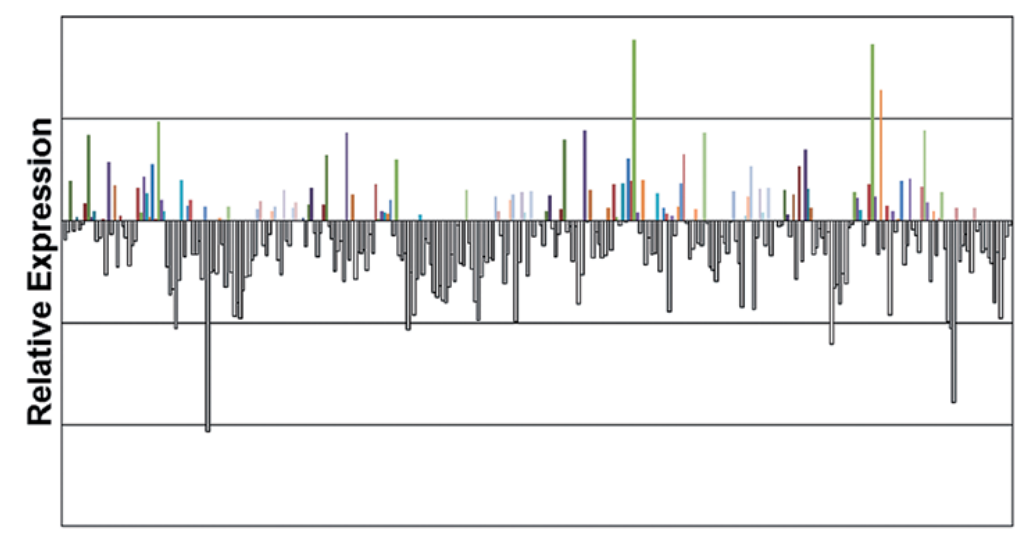

and 65.8\%, respectively, in prostate cancer tissue, compared to benign prostate tissue.

We found differences in MMP-2 and TIMP2 expression between high-grade $\mathrm{PCa}$ (Gleason $\geq$ 7) versus low-grade PCa (Gleason $<7$ ). The median expression of MMP-2 was 0.84 for high-grade PCa vs. 0.52 for low-grade tumors $(\mathrm{p}=0.048)$. The median expression of TIMP-2 was 0.59 vs. 0.39 for high-grade and low-grade PCa, respectively ( $p$ pathological stage, PSA pre-operatory serum levels or biochemical recurrence.

\section{DISCUSSION}

In the present study we demonstrated that MMP-2 and its regulators are underexpressed in PCa compared to BPH tissue. Others, studying different types of cancer, have found overexpression 
Table 3 - Relative expression of the four genes in malignant prostatic tissue according to Gleason scores, pathological stages, PSA values and biochemical recurrence. Fold changes in gene expression were calculated using the $\Delta \Delta C T$ method ( $\left.\mathrm{QRel}=2-{ }^{\Delta \Delta C \mathrm{~T}}\right)$.

\begin{tabular}{|c|c|c|c|c|}
\hline & MMP2 & TIMP2 & MMP14 & IL8 \\
\hline \multicolumn{5}{|l|}{ Gleason Score } \\
\hline$<7(\mathrm{n}=32)$ & $\begin{array}{c}0.520 \\
(0.3-1.0)\end{array}$ & $\begin{array}{c}0.391 \\
(0.3-0.7)\end{array}$ & $\begin{array}{c}0.657 \\
(0.4-1.2)\end{array}$ & $\begin{array}{c}0.839 \\
(0.5-1.3)\end{array}$ \\
\hline$\geq 7(n=36)$ & $\begin{array}{c}0.844 \\
(0.4-1.4)\end{array}$ & $\begin{array}{c}0.598 \\
(0.4-1.2)\end{array}$ & $\begin{array}{c}0.890 \\
(0.5-1.7)\end{array}$ & $\begin{array}{c}0.689 \\
(0.4-1.3)\end{array}$ \\
\hline$p$-value & 0.048 & 0.021 & 0.081 & 0.274 \\
\hline \multicolumn{5}{|l|}{ Pathological Stage } \\
\hline pT2 $(n=37)$ & $\begin{array}{c}0.737 \\
(0.3-1.3)\end{array}$ & $\begin{array}{c}0.493 \\
(0.2-1.2)\end{array}$ & $\begin{array}{c}0.894 \\
(0.5-1.7)\end{array}$ & $\begin{array}{c}0.767 \\
(0.4-1.3)\end{array}$ \\
\hline pT3 $(n=40)$ & $\begin{array}{c}0.630 \\
(0.3-1.3)\end{array}$ & $\begin{array}{c}0.474 \\
(0.3-0.7)\end{array}$ & $\begin{array}{c}0.690 \\
(0.4-1.3)\end{array}$ & $\begin{array}{c}0.629 \\
(0.4-1.3)\end{array}$ \\
\hline$p$-value & 0.510 & 0.955 & 0.332 & 0.537 \\
\hline \multicolumn{5}{|l|}{ PSA value } \\
\hline$<10(\mathrm{n}=45)$ & $\begin{array}{c}0.655 \\
(0.3-1.3)\end{array}$ & $\begin{array}{c}0.479 \\
(0.3-0.9)\end{array}$ & $\begin{array}{c}0.780 \\
(0.4-1.3)\end{array}$ & $\begin{array}{c}0.577 \\
(0.3-1.2)\end{array}$ \\
\hline$\geq 10(n=33)$ & $\begin{array}{c}0.689 \\
(0.3-1.3)\end{array}$ & $\begin{array}{c}0.482 \\
(0.3-1.2)\end{array}$ & $\begin{array}{c}0.886 \\
(0.4-2.0)\end{array}$ & $\begin{array}{c}0.767 \\
(0.5-1.5)\end{array}$ \\
\hline $\mathrm{p}$-value & 0.831 & 0.738 & 0.616 & 0.195 \\
\hline \multicolumn{5}{|c|}{ Biochemical Recurrence } \\
\hline$W / n(n=29)$ & $\begin{array}{c}0.868 \\
(0.4-1.1)\end{array}$ & $\begin{array}{c}0.522 \\
(0.3-0.8)\end{array}$ & $\begin{array}{c}0.882 \\
(0.5-1.2)\end{array}$ & $\begin{array}{c}0.528 \\
(0.3-1.0)\end{array}$ \\
\hline With $(n=28)$ & $\begin{array}{c}0.992 \\
(0.4-1.5)\end{array}$ & $\begin{array}{c}0.587 \\
(0.3-1.6)\end{array}$ & $\begin{array}{c}1.037 \\
(0.5-2.2)\end{array}$ & $\begin{array}{c}0.912 \\
(0.5-1.3)\end{array}$ \\
\hline$p$-value & 0.482 & 0.518 & 0.538 & 0.148 \\
\hline
\end{tabular}

of these genes $(11,12)$. However, there are reports showing that the absence of some MMP can be related to the promotion of tumors. For instance, Balbin et al., has described an increased susceptibility to skin cancer in mice that didn't express MMP-8 (13). Our results are similar to those published by Lichtinghagen et al. (2002) (14), who showed MMP-2 underexpression in prostate can- cer tissue using RT-PCR. Conversely, they observed higher expression of MMP-2 at the protein level using immunohistochemistry, a result later confirmed by Brehmer et al. (15), indicating that there is a discrepancy between the levels of MMP-2 mRNA and protein in prostate cancer.

Interestingly, we found an association between elevated expression of MMP-2 and TIMP-2 
and Gleason scores $\geq 7$, while MT1-MMP, which was also expressed at a higher level in Gleason scores $\geq 7$, only reached a level of marginal statistical significance $(p=0.08)$. The Gleason score is the main prognostic parameter for $\mathrm{PCa}$, and it dictates the therapeutics in the majority of cases, although there are many pitfalls to use it as a determining factor. Because treatment options range from watchful waiting to palliative androgen deprivation, the correct characterization of histological differentiation is especially valuable for the correct treatment of the neoplasia. We have previously shown that it is possible to downgrade and upgrade PCa Gleason scores in radical prostatectomies to values of $14 \%$ and $29 \%$, respectively, showing the weakness of using it as a prognostic factor, even when utilized by an experienced uropathologist (16). This confirms the necessity for additional biological information regarding $\mathrm{PCa}$ behavior. This is the first time that a study has shown a correlation between Gleason scores and MMP-2/TIMP-2 mRNA expression in PCa.

Extensive studies have revealed that malignant invasion and metastasis require ECM degradation, mainly by MMPs (17). Excessive or inappropriate expression of MMPs may contribute to the pathogenesis of cancer in a wide variety of cases by facilitating tissue degradation. Currently, there are more than 20 identified MMPs that can be categorized by substrate specificity. Despite the clinical significance of the pathogenetic impact of MMPs in human cancer, including PCa, only a few studies of MMPs are available in the literature, and those mainly analyze protein expression (18).

Among the identified MMPs, MMP2 cleaves type IV collagen and gelatin, which are the main structural components of the basal membrane in the ECM, and the ECM is the first vital barrier on the course of tumor metastasis. Based on these findings, MMP-2 is thought to contribute to matrix breakdown. Today it is clear that MMP-2 participates in many deregulated signaling pathways that are used by the tumor to promote cancer cell growth and angiogenesis. The fact that we are already aware of these attributes makes MMP-2 a promising prognostic marker (19).
Interestingly, we found that MMP2 is underexpressed in prostate cancer, indicating that this MMP is not related to the promotion of PCA. However, after the establishment of the tumor, an increase in expression of MMP2 may be involved in tumor differentiation, which explains the association of elevated MMP2 expression in highgrade tumors. Miyake et al. (2010) (20), using immunohistochemistry showed that in univariate analysis MMP2 expression was significantly associated with biochemical recurrence, demonstrating the importance of this gene in the progression of $\mathrm{PCa}$.

At the post-translational level, MMPs are under the control of specific tissue inhibitors (TIMPs) that bind proximal to the catalytic domain of the MMPs, preventing substrate binding. TIMPs are not simply regulators of MMP activity; they also have multifunctional roles that include cell growth promotion (8) and inhibition of angiogenesis (21). At the time of their discovery, TIMPs were considered to be tumor suppressor proteins. Increased TIMP expression is currently associated with decreased tumor growth, invasiveness and metastasis in prostate cancer and other cancer cell lines (22). However, the results of the current study demonstrate a poor prognostic significance of increased TIMP-2 expression, which is contrary to the original tumor-suppressor role that TIMPs were hypothesized to play. These results, however, are in agreement with recent evidence that supports a multifunctional and complex role for TIMPs. Nemeth et al. (23) described the growthpromoting abilities of TIMP-2 in several human cell types, including fibroblasts, keratocytes, lymphocytes and stem cells. Increased TIMP1 and TIMP2 mRNA levels have been correlated with higher tumor stages, lymph node metastasis and shortened survival in patients with carcinoma of the colon (24), breast (25), or bladder (26).

Although the paradoxical positive effects of TIMPs on tumor progression are not completely understood, the tumor promoting activity may be due either to proteolytic degradation of ECM or a direct influence on cell survival and growth. Stimulation of cell growth by TIMPs is thought to be mediated by cAMP-dependent activation of protein Kinase A and increased tyrosine phosphorylation (26). 
TIMP-2 is reported to regulate matrix degradation, acting through a membrane type MMP (MT1-MMP). MT1-MMP is a key enzyme in tumor angiogenesis and metastasis: it hydrolyzes a variety of ECM components, and is a physiological activator of pro-MMP-2 (27). TIMP-2 forms a complex with MT1-MMP on the cell surface promoting hydrolysis of pro-MMP2 to its active form resulting in degradation of ECM.

We have shown that even with decreased MMP-2, TIMP-2 and MT1-MMP gene expression in cancer tissue, there was an increased expression in patients with Gleason scores $\geq 7$, an important prognostic factor of this disease. But we were not able to show a correlation between MMP-2, TIMP-2, MT1-MMP and IL-8, and the outcome of the disease following a 60-month period of follow-up. This lack of supporting evidence in this regard can be attributed to the small number of cases in each group.

We can postulate that the low expression of TIMP-2, MT1-MMP and IL-8 may be responsible for the decreased MMP-2 expression in PCa tissue, and this profile might be a characteristic of prostate cancer that can be utilized for tumor diagnosis in the future. Also, the fact that MMP-2 and TIMP-2 expression levels increase with tumor grade suggests that these genes might be involved in the differentiation of prostate cancer.

\section{ACKNOWLEDGEMENTS}

Grant sponsors: This study was supported by FAPESP (Fundação de Amparo à Pesquisa do Estado de São Paulo) under protocol number 2009/50368-9

\section{CONFLICT OF INTEREST}

None declared.

\section{REFERENCES}

1. Siegel R, Ward E, Brawley 0, Jemal A: Cancer statistics, 2011: the impact of eliminating socioeconomic and racial disparities on premature cancer deaths. CA Cancer J Clin. 2011; 61: 212-36.
2. Berger AP, Spranger R, Kofler K, Steiner H, Bartsch G, Horninger $\mathrm{W}$ : Early detection of prostate cancer with low PSA cut-off values leads to significant stage migration in radical prostatectomy specimens. Prostate. 2003; 57: 93-8.

3. Toi M, Ishigaki S, Tominaga T: Metalloproteinases and tissue inhibitors of metalloproteinases. Breast Cancer Res Treat. 1998; 52: 113-24.

4. Eissa S, Ali-Labib R, Swellam M, Bassiony M, Tash F, ElZayat TM: Noninvasive diagnosis of bladder cancer by detection of matrix metalloproteinases (MMP-2 and MMP-9) and their inhibitor (TIMP-2) in urine. Eur Urol. 2007; 52: 1388-96.

5. Liabakk NB, Talbot I, Smith RA, Wilkinson K, Balkwill F: Matrix metalloprotease 2 (MMP-2) and matrix metalloprotease 9 (MMP-9) type IV collagenases in colorectal cancer. Cancer Res. 1996; 56: 190-6.

6. Sato H, Takino T, Kinoshita T, Imai K, Okada Y, Stetler Stevenson WG et al.: Cell surface binding and activation of gelatinase $A$ induced by expression of membrane-type1-matrix metalloproteinase (MT1-MMP). FEBS Lett. 1996; 385: 238-40.

7. Jovanović M, Stefanoska I, Radojcić L, Vićovac L. Interleukin-8 (CXCL8) stimulates trophoblast cell migration and invasion by increasing levels of matrix metalloproteinase (MMP)2 and MMP9 and integrins alpha5 and beta1. Reproduction. 2010; 139: 789-98.

8. Henriet P, Blavier L, Declerck YA. Tissue inhibitors of metalloproteinases (TIMP) in invasion and proliferation. APMIS. 1999; 107: 111-9.

9. Nawrocki B, Polette M, Marchand V, Monteau M, Gillery P, Tournier JM et al.: Expression of matrix metalloproteinases and their inhibitors in human bronchopulmonary carcinomas: quantificative and morphological analyses. Int J Cancer. 1997; 72: 556-64.

10. Polette M, Nawrocki-Raby B, Gilles C, Clavel C, Birembaut $P$ : Tumour invasion and matrix metalloproteinases. Crit Rev Oncol Hematol. 2004; 49: 179-86.

11. Tang ZG, Li JM, Hong ZZ, Yu ZW, Liu CH: Expression of matrix metalloproteinase 2 in oral verruvous carcinoma and squamous cell carcinoma. Zhong Nan Da Xue Xue Bao Yi Xue Ban. 2005; 30: 650-2.

12. Scrideli CA, Cortez MA, Yunes JA, Queiróz RG, Valera ET, da Mata JF et al.: mRNA expression of matrix metalloproteinases (MMPs) 2 and 9 and tissue inhibitor of matrix metalloproteinases (TIMPs) 1 and 2 in childhood acute lymphoblastic leukemia: potential role of TIMP1 as an adverse prognostic factor. Leuk Res. 2010; 34: 32-7.

13. Balbín M, Fueyo A, Tester AM, Pendás AM, Pitiot AS, Astudillo $A$ et al.: Loss of collagenase-2 confers increased skin tumor susceptibility to male mice. Nat Genet. 2003; 35: 252-7. 
14. Lichtinghagen R, Musholt PB, Lein M, Römer A, Rudolph $B$, Kristiansen $G$ et al.: Different mRNA and protein expression of matrix metalloproteinases 2 and 9 and tissue inhibitor of metalloproteinases 1 in benign and malignant prostate tissue. Eur Urol. 2002; 42: 398-406.

15. Brehmer B, Biesterfeld S, Jakse G. Expression of matrix metalloproteinases (MMP-2 and -9 ) and their inhibitors (TIMP-1 and -2) in prostate cancer tissue. Prostate Cancer Prostatic Dis. 2003; 6: 217-22.

16. Moreira Leite KR, Camara-Lopes LH, Dall'Oglio MF, Cury J, Antunes AA, Sañudo A et al.: Upgrading the Gleason score in extended prostate biopsy: implications for treatment choice. Int J Radiat Oncol Biol Phys. 2009; 73: 353-6.

17. Zhong WD, Han ZD, He HC, Bi XC, Dai QS, Zhu G et al.: CD147, MMP-1, MMP-2 and MMP-9 protein expression as significant prognostic factors in human prostate cancer. Oncology. 2008; 75: 230-6.

18. Simi L, Andreani M, Davini F, Janni A, Pazzagli M, Serio $M$ et al.: Simultaneous measurement of MMP9 and TIMP1 mRNA in human non small cell lung cancers by multiplex real time RT-PCR. Lung Cancer. 2004; 45: 171-9.

19. Egeblad M, Werb Z: New functions for the matrix metalloproteinases in cancer progression. Nat Rev Cancer. 2002; 2: $161-74$

20. Miyake H, Muramaki M, Kurahashi T, Takenaka A, Fujisawa $M$ : Expression of potential molecular markers in prostate cancer: correlation with clinicopathological outcomes in patients undergoing radical prostatectomy. Urol Oncol. 2010; 28: 145-51.

21. Cox G, Jones JL, Walker RA, Steward WP, O'Byrne KJ. Angiogenesis and non-small cell lung cancer. Lung Cancer. 2000; 27: 81-100.
22. Rabbani SA, Harakidas P, Guo Y, Steinman D, Davidsen SK, Morgan DW: Synthetic inhibitor of matrix metalloproteases decreases tumor growth and metastases in a syngeneic model of rat prostate cancer in vivo. Int J Cancer. 2000; 87: 276-82.

23. Nemeth JA, Rafe A, Steiner M, Goolsby CL. TIMP-2 growthstimulatory activity: a concentration- and cell type-specific response in the presence of insulin. Exp Cell Res. 1996; 224: $110-5$.

24. Murashige M, Miyahara M, Shiraishi N, Saito T, Kohno K, Kobayashi M: Enhanced expression of tissue inhibitors of metalloproteinases in human colorectal tumors. Jpn J Clin Oncol. 1996; 26: 303-9.

25. Ree AH, Florenes VA, Berg JP, Maelandsmo GM, Nesland JM, Fodstad 0: High levels of messenger RNAs for tissue inhibitors of metalloproteinases (TIMP-1 and TIMP-2) in primary breast carcinomas are associated with development of distant metastases. Clin Cancer Res. 1997; 3: 1623-8.

26. Grignon DJ, Sakr W, Toth M, Ravery V, Angulo J, Shamsa F et al.: High levels of tissue inhibitor of metalloproteinase-2 (TIMP-2) expression are associated with poor outcome in invasive bladder cancer. Cancer Res. 1996; 56: 1654-9.

27. Strongin AY, Collier I, Bannikov G, Marmer BL, Grant GA, Goldberg Gl: Mechanism of cell surface activation of 72$\mathrm{kDa}$ type IV collagenase. Isolation of the activated form of the membrane metalloprotease. J Biol Chem. 1995; 270: $5331-8$.

Correspondence address:

Dr. Katia Ramos Moreira Leite

Av. Dr. Arnaldo 455, $2^{\circ}$ floor, room 2145 01246-903, Sao Paulo, SP, Brazil

E-mail: katiaramos@uol.com.br 